\title{
New Orientation of the Editorial Board
}

\author{
Rolf Henke $^{1}$ - Cornelia Hillenherms ${ }^{1}$
}

Published online: 5 August 2015

(c) Deutsches Zentrum für Luft- und Raumfahrt e.V. 2015

The CEAS Aeronautical Journal is now in its fifth year of publication and it has become well recognised in European circles for its presentation of new developments and outstanding results in the field of aeronautical science and technology. However, after this initial phase we felt the need to adapt the journal to keep up with the development in aeronautical science and technology as well as with the demands of scientific publishing.

One important aspect in scientific publishing is international diversity since the research community and the audience are international. Furthermore, taking into account the governing topics of the submitted manuscripts, we have decided to re-organise the editorial fields. The journal now covers fields like Aeroelasticity and Structural Mechanics and Systems separately. Flight GuidancelATM is complemented by $C N S / G N C$, and Aircraft by Aircraft Design. Hence, we invited new field editors to become more international and to fill the new fields. To keep the size of the editorial board more or less constant, we have also decided to limit the duration of the editorial board membership to a five-year term basically, allowing extensions.

With this issue, I am pleased to announce some changes to the editorial board composition:

Prof. Dr. Sergio Ricci from Politecnico di Milano (Italy) was appointed as Field Editor for Aeroelasticity and Structural Mechanics, Bruno Lamiscarre from ONERA
(France) was appointed for Flight Mechanics/Flight Control, Jean Hermetz from ONERA (France) was appointed for Systems, Peter Schmollgruber from ONERA (France) and Prof. Dr. Sara Bagassi from Università di Bologna (Italy) were appointed for Aircraft/Aircraft Design, and Francois Falempin from MBDA (France) was appointed for Propulsion. We are very pleased to welcome these experts at the editorial board and look forward to their contributions to the CEAS Aeronautical Journal.

We would like to express our sincere gratitude to the previous board members, Dr. John E. Green, Craig Mead, Prof. Dr. Frank Thielecke, Prof. Dr. Peter Hecker, and Prof. Günter Albrecht, who supported the journal from its beginning with their dedicated and valuable advice, contributed significantly to its success, and now give the floor to the new members. We would be glad to see them still following the journal's way forward and provide us senior advice.

We are convinced you will appreciate these changes to the editorial board composition as they fit well with our goal of increasing the CEAS Aeronautical Journal's visibility and impact.

Prof. Rolf Henke, Editor-in-Chief

Dr. Cornelia Hillenherms, Managing Editor

Cornelia Hillenherms

Cornelia.Hillenherms@dlr.de

1 German Aerospace Center (DLR), Linder Höhe, 51147 Cologne, Germany 